\title{
BF-Catalyzed High Pressure Synthesis of Acetic Acid from Methanol and Carbon Monoxide
}

\section{$\operatorname{AUTHOR}(\mathrm{S}):$}

Takezaki, Yoshimasa; Kawatani, Tsuneo; Sugita, Nobuyuki; Yuasa, Sachio; Osugi, Minoru; Suzuki, Yoshiko

\section{CITATION:}

Takezaki, Yoshimasa ... [et al]. BF-Catalyzed High Pressure Synthesis of Acetic Acid from Methanol and Carbon Monoxide. Bulletin of the Institute for Chemical Research, Kyoto University 1961, 39(4-5): 325-326

\section{ISSUE DATE:}

1961-11-15

URL:

http://hdl.handle.net/2433/75847

RIGHT: 


\title{
Preparation of Crystalline Polyaldehydes
}

\author{
Junji Furukawa, Takeo Saegusa and Hiroyasu Fujn
}

Makromol. Chem. 44-46, 398 1961)

We found that some organometallic compounds and metal alkoxides polymerized aldehydes including acetaldehyde, propionaldehyde and trichloroacetaldehyde (anhydrous chloral) to give crystalline polyaldehydes. Crystalline polyacetaldehyde was much less soluble in organic solvents than the amorphous one.

Active species of this polymerization was supposed to be metal alkoxide and the mechanism of polymerization was considered in connection with several synthetic organic reactions which involve metal alkoxides and carbonyl compounds. It was assumed that the coordination of aldehyde to the metal alkoxide was essential in propagation reaction which determined the stereospecificity of the polymer produced.

\section{$\mathrm{BF}_{3}$-Catalyzed High Pressure Synthesis of Acetic Acid from Methanol and Carbon Monoxide}

\author{
Yoshimasa Takezaxi, Tsuneo Kawatani, Nobuyuki Sugrta, \\ Sachio Yuasa, Minoru Osugr and Yoshiko Suzuri
}

Bulletin of the Japan Petroleum Institute, 2, 94 (1960)

The reaction of acetic acid synthesis from $\mathrm{MeOH}$ and $\mathrm{CO}$ has been investigated kinetically in the presence of $\mathrm{BF}_{3} \cdot 4 \mathrm{H}_{2} \mathrm{O}$ as catalyst, as shown by

$$
\mathrm{CH}_{3} \mathrm{OH}+\mathrm{CO} \stackrel{\mathrm{BF}_{3}}{\rightarrow} \rightarrow \mathrm{CH}_{3} \mathrm{COOH} \text {. }
$$

The following results have been found out:

1) Preliminary experiments on the system $\mathrm{BF}_{3} / \mathrm{H}_{2} \mathrm{O} / \mathrm{MeOH} / \mathrm{AcOH}$ : On atmospheric distillation of the mixture $\mathrm{MeOH} / \mathrm{BF}_{3} / \mathrm{H}_{2} \mathrm{O} / \mathrm{AcOH}$ (mole ratio $1 / 0.25 / 1 / 0.8$ ) with a Widmer column, $\mathrm{AcOH}, \mathrm{MeOH}$ and $\mathrm{H}_{2} \mathrm{O}$ are distilled out until $106^{\circ} \mathrm{C}$ and the residue is of the composition $(0 / 0.5 / 1 / 0.1)$.

When the mixture of $\mathrm{MeOH} / \mathrm{BF}_{3} / \mathrm{H}_{2} \mathrm{O}(1 / 0.5 / 1)$ is heated in the autoclave up to $335^{\circ} \mathrm{C}$, vapor pressure reaches 66 atm., and both of $\mathrm{BF}_{3}$ and $\mathrm{H}_{2} \mathrm{O}$ remain in the liquid phase, and free $\mathrm{MeOH}$ is in the dehydration equilibrium with MeOMe and each gaseous component ( $\mathrm{MeOH}$ and $\mathrm{MeOMe}$ ) is also in equilibrium with each dissolved in the liquid phase. The dehydration equilibrium constant $K$ and Henry's constants, $K^{\prime}{ }_{\mathrm{m}}$ and $K_{\mathrm{e}}^{\prime}$, have been obtained at $335^{\circ} \mathrm{C}$ as below:

$$
\begin{aligned}
\mathrm{CH}_{3} \mathrm{OH} \rightleftarrows & \frac{1}{2} \mathrm{MeOMe}+\frac{1}{2} \mathrm{HO}_{2} \text { (gas phase), } K=P_{\mathrm{e}}{ }^{1 / 2} P_{\mathrm{H} 2 \mathrm{O}^{1 / 2}} / P_{\mathrm{m}}=2.13 \\
& \left.M_{\mathrm{m}}^{\prime} / V_{l}=k_{\mathrm{m}}^{\prime} P, k_{\mathrm{m}}^{\prime}=4.56 \times 10^{-4} \text { (mol. c.c. }{ }^{-1} \text { atm. }{ }^{-1}\right) \\
& M_{\mathrm{e}}^{\prime} / V_{l}=k_{\mathrm{e}}^{\prime} P, \quad k_{\mathrm{e}}^{\prime}=7.25 \times 10^{-5} \text { (mol.c.c. }{ }^{1-} \text { atm. }{ }^{1-} \text { ) }
\end{aligned}
$$

where, suffix $\mathrm{m}$ stands for $\mathrm{MeOH}$ and e for MeOMe.

$M^{\prime}=$ moles in liq., $V_{l}=$ liq. volume, $P=$ pressure. 


\section{ABSTRACTS}

2) Effect of $\mathrm{CO}$ pressure ( $560 \sim 1030 \mathrm{~atm}$., $\mathrm{MeOH} 0.5 M, \mathrm{BF}_{8} \cdot 4 \mathrm{H}_{2} \mathrm{O} 0.125 M, 335^{\circ} \mathrm{C}$ ):

The initial rate is proportional to the fugacity of $\mathrm{CO}$, and the yield is over the stoichiometrical amount of $\mathrm{BF}_{3}$, for instance $0.4 \mathrm{M}$ of $\mathrm{AcOH}$ is produced under $860 \mathrm{~atm}$. of $\mathrm{CO}$ and $0.125 \mathrm{M}$ of $\mathrm{BF}_{3}$ in $2 \mathrm{hrs}$.

3) Effect of temperature $\left(320 \sim 360^{\circ} \mathrm{C}, \mathrm{CO} 800 \mathrm{~atm}\right.$, $\mathrm{MeOH} 0.5 M, \mathrm{BF}_{3} \cdot 4 \mathrm{H}_{2} \mathrm{O}$ $0.125 M)$ : Initial velocities $(\mathrm{dx} / \mathrm{dt})_{t=o} \times 10^{3}$, are 26.2 at $360^{\circ} \mathrm{C}, 10.6$ at $340^{\circ} \mathrm{C}$ and 4.4 at $320^{\circ} \mathrm{C}$

4) Effect of $\mathrm{MeOH}$ charge amount: Under the fixed conditions of $335^{\circ} \mathrm{C}$, $800 \sim 850 \mathrm{~atm}$. and $\mathrm{BF}_{3} 0.125 \mathrm{M}$, the yield drops the charge of $\mathrm{MeOH}$ is raised, for instance $97 \%$ yield for charged $\mathrm{MeOH} 0.5 \mathrm{M}$ and $1 \mathrm{hr}$., but only $10 \%$ for charged $\mathrm{MeOH} 1.0 \mathrm{M}$ in a reactor of 130 c.c.

The linear relationship is obtained between the initial velocity and $\mathrm{MeOH}$ equilibrium concentration in the liquid.

5) From the above-mentioned results, the initial rate equation has been obtained as shown next:

$$
(\mathrm{dx} / \mathrm{dt})_{t=0}=\left(k f_{\mathrm{co}} k_{\mathrm{m}}^{\prime} / 4 a e V_{\mathrm{f}}\right)\left[-\left(m / M_{0}\right)+\left\{\left(m / M_{0}\right)^{2}+(8 a e / M)^{1 / 2}\right\}\right]
$$

where, $x=$ produced $\mathrm{AcOH} /$ charged $\mathrm{MeOH}(M / M)$,

$$
\begin{aligned}
& a=K^{2} R T / P_{\mathrm{H}_{2} \mathrm{O}} V_{\mathrm{f}}, b=R T V_{l} / V_{\mathrm{f}}, m=1+k_{\mathrm{m}}^{\prime} b, \\
& e=1+k_{\mathrm{e}}^{\prime} b, a=9060 / V_{\mathrm{f}}, b=49900 / V_{\mathrm{f}},
\end{aligned}
$$

$M=$ charged $\mathrm{MeOH}(M), V=$ free space of autoclave.

Rate constants $k^{\prime}$ s have been calculated to be $3.97 \times 10^{-5}\left(\mathrm{~atm}^{-1} \cdot \mathrm{min}^{-1}\right.$ ) at $350^{\circ} \mathrm{C}, 2.37 \times 10^{-5}$ at $335^{\circ} \mathrm{C}$ and $1.62 \times 10^{-5}$ at $320^{\circ} \mathrm{C}$. The activation energy of $22 \mathrm{Kcal}$./ mol. has been obtained.

\section{Synthesis of Dimethylformamide from Methanol, Ammonia and Carbon Monoxide under High Pressure}

Yoshimasa Takezakr, Yoshiharu Kitahama, Yoshiko Suzukr, Nobuyuki Sugrta and Sachio YuAsa

Kogyokagaku Zasshi (Journal of the Chemical Society of Japan, Industrial Chemistry Section), 63, 1739 (1960)

The effects of reaction conditions on the one step synthesis of dimethylformamide from $\mathrm{MeOH}, \mathrm{NH}_{3}$ and $\mathrm{CO}$ have been studied under high pressure in the presence of AcOK as a catalyst. Stoichiometrically the reaction is represented as below, but it is very interesting to know whether the reaction proceeds in one step or in two steps, i. e. methylation followed by formylation.

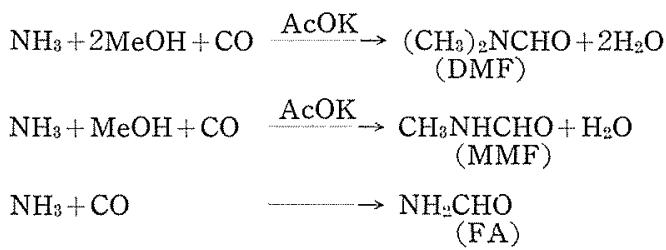

1) The effect of reaction temperature $\left(220 \sim 340^{\circ} \mathrm{C}\right)$ : The increase of DMA yield and the decrease of MMF and DMF above $280^{\circ} \mathrm{C}$ are due to the instability 